\title{
The return of individual research findings in paediatric genetic research
}

\author{
Kristien Hens, ${ }^{1}$ Herman Nys, ${ }^{1}$ Jean-Jacques Cassiman, ${ }^{2}$ Kris Dierickx ${ }^{1}$
}

${ }^{1}$ Katholieke Universiteit Leuven, Centre for Biomedical Ethics and Law, Leuven, Belgium ${ }^{2}$ Katholieke Universiteit Leuven, Departement Menselijke Erfelijkheid, Leuven, Belgium

\section{Correspondence to}

Dr Kristien Hens, Katholieke Universiteit Leuven, Centre for Biomedical Ethics and Law, Kapucijnenvoer 35/3 Box 7001, 3000 Leuven, Belgium; kristien.hens@med.kuleuven.be

Received 28 April 2010 Revised 13 July 2010 Accepted 4 October 2010 Published Online First 8 November 2010

\section{ABSTRACT}

The combination of the issue of return of individual genetic results/incidental findings and paediatric biobanks is not much discussed in ethical literature. The traditional arguments pro and con return of such findings focus on principles such as respect for persons, autonomy and solidarity. Two dimensions have been distilled from the discussion on return of individual results in a genetic research context: the respect for a participant's autonomy and the duty of the researcher. Concepts such as autonomy and solidarity do not fit easily in the discussion when paediatric biobanks are concerned. Although parents may be allowed to enrol children in minimal risk genetic research on stored tissue samples, they should not be given the option to opt out of receiving important health information. Also, children have a right to an open future: parents do not have the right to access any genetic data that a biobank holds on their children. In this respect, the guidelines on genetic testing of minors are applicable. With regard to the duty of the researcher the question of whether researchers have a more stringent duty to return important health information when their research subjects are children is more difficult to answer. A researcher's primary duty is to perform useful research, a policy to return individual results must not hamper this task. The fact that vulnerable children are concerned, is an additional factor that should be considered when a policy of returning results is laid down for a specific collection or research project.

Paediatric biobanks and longitudinal studies involving children form an excellent resource to study the genetic components of conditions that affect children. However, such collections also raise ethical questions that are not completely analogous to those raised by collections containing only adult material and data. ${ }^{1}$ As a recent literature review has shown, the issue of the validity of parental consent to research on children's DNA, as well as the privacy risks associated with the storage of paediatric stored tissue samples and data has been discussed in some ethical papers already. ${ }^{2}$ The protection of children has also been the subject of a Policy Forum in Science. ${ }^{3-6}$

Next to the issue of paediatric biobanks, another topic much discussed in the recent biobank literature is the return of individual research findings. ${ }^{7}$ The major questions asked are whether biobanks should return such individual results to participants and if so, which results should be returned. Such research findings may have two forms: there may be individual findings that are to be expected based on the study design, and there may be incidental findings, certain anomalies that were not originally looked for. ${ }^{8}$ To date the chance that researchers may find genetic conditions that they may not be looking for may seem low. However, with the advent of new techniques, such findings may become more frequent. For example, array comparative genomic hybridization may be used to study the relation between a certain phenotype and a copy number variation in a paediatric population..$^{9}$ As the resolution that can be acquired with this technique can be quite high, it is not unthinkable that other significant variations are discovered next to the variations under investigation. ${ }^{10}$ Also, with the rise of genome-wide association studies studies, it is possible that variants are found whose significance is not so clear; for example, they could point to the possibility of lateonset conditions. ${ }^{11}$ With the vast increase of knowledge in the field of genetics it can be expected that these situations will occur more frequently and require a thorough investigation.

We admit that the question about the return of individual results in genetic research is quite complex. It is nearly impossible to give an answer fitting all situations. The answer is highly dependent on different variables: the type of genetic information found, the context (research-only or research that is still somewhat linked to a diagnostics context) and the capabilities of the researchers. The type of biobank and modes of recruitment can also be deciding factors, as the duty to return results is higher when the recruiter is a general practitioner (GP) or clinician in frequent contact with a patient than when the recruiter is a researcher or research nurse and the contact is one off. Also, the question is multilayered: what information should be returned by the researcher to a clinical geneticist and/or GP and what information should be returned by the latter or the former to the research participants themselves? There is an aspect of contingency when incidental findings are concerned: a researcher working on certain genes may be unaware of the significance of a variation that is outside her field. Therefore, not all researchers may be able to feed all potentially relevant information back. As we will demonstrate, we have discovered two dimensions to the question, which are often confounded in the literature: the duty of the researcher to inform versus the right of the participants to know such information. These two dimensions, however, cannot be reduced to one another.

In the next sections we will first describe the arguments that are usually given pro and con the return of individual research results. We will give an overview of the general discussion, which focuses 
on adult participants. Then we will describe our own viewpoint on the matter. We will end with recommendations for policy makers. In this paper we will use individual research results both for the findings that are to be expected in the context of a study and for incidental findings. We acknowledge that there may be subtle differences in the ethical dealings with the two kinds of findings, but for the limited scope of this paper they can be treated simultaneously; as the net result is very much alike.

\section{OVERVIEW OF THE ARGUMENTS}

In the past few years, many articles have discussed the pros and cons of return of individual genetic results in a research context, specifically with adult participants in mind. In the theoretical literature, we basically find three viewpoints here, and some variants. A first line of thought is that individual research results should never be returned to research participants. Arguments for this stance are that genetic results are usually inconclusive, and as such can cause anxiety. ${ }^{12}$ Authors also refer to the therapeutic misconception: returning results could give the impression to research participants that the research is for their own personal benefit. Particularly in large biobank contexts there is no need for researchers to take on the task of clinicians, because these are primarily focused on the advance of public health. ${ }^{13}$ Also returning individual results is considered too resource intensive. ${ }^{14}$ An example of a biobank with a policy of not returning individual results is the UK Biobank. ${ }^{15}$

A second line of thought states that all individual results should be given to the research participants if they do so want, as research participants should not be treated as mere means to (research) ends. Respect for participants means respecting their autonomy. ${ }^{16}$ Returning individual results may also ensure better enrolment. ${ }^{17}$ The Estonian Gene Bank is an example of a biobank that recruits through GPs and allows individuals to access their records and genetic data, but not genealogical information. It also provides genetic counselling. ${ }^{i}$ The Council for International Organization of Medical Sciences guideline on epidemiology specifies that individuals must be informed about their health status. ${ }^{18}$

A third line of thought is reflected in the WHO report on genetic databases ${ }^{19}$ and in a paper by Bookman et al, ${ }^{20}$ and states that individuals have a right to individual research results if these are of clinical significance, scientific valid and if they provide a potential benefit to the participants. A National Institutes of Health-proposed large cohort study is of this type. ${ }^{17}$ Related to this is the idea of the ancillary duty of care. ${ }^{21}$ This concept is based on the idea that when participants signed up for a study they partly entrust certain aspects of their health into the researcher's hands. So if something is found that can significantly increase the health of a participant, this information should be returned. However, this does not imply that researchers have an active duty to hunt for findings.

There are several variants of the above positions. ${ }^{22}$ The much discussed paper of Ravitsky and Wilfond ${ }^{23}$ proposes a resultevaluation approach based on analytical validity, clinical utility, context of study, personal meaning to study participants and the nature of the participant-researcher relationship. An approach called 'tiered disclosure' by Rothstein ${ }^{24}$ suggests that participants could select from options for research disclosure when they enrol for the study.

From the above arguments, we can distill two dimensions of the question. These dimensions influence each other but cannot

i http://www.geenivaramu.ee/index.php?id=110. be reduced to one another. First, there is the question of the right of the participants to decide for themselves if and what information they should receive. Second, there is the duty of the researcher to return information that has clinical significance and can be validated. An emphasis on the right to know of the participant may influence the duty of the researcher, but there may be valid grounds to relieve the latter of this duty. This does not automatically imply a disrespect of the former. Moreover, there may be situations in which the researcher may have the duty to return certain findings if the wishes of the participants are unknown, or even contrary to their wishes.

\section{RETURN OF INDIVIDUAL RESULTS IN PAEDIATRIC BIOBANKS}

We believe that the question of returning individual results for paediatric participants does not easily fit in the above models. We will formulate our own thoughts under the two dimensions sketched above: 'participant autonomy' and 'duty of researcher'. To conclude, we will formulate some recommendations that can be used by policy makers.

\section{Participant autonomy}

A first dimension in the ethical reflection on the return of individual results in genetic research on stored tissue samples is related to the autonomy principle and the right of participants to decide whether they want to receive certain information about their health or not. Authors that stress this autonomy would opt for the second line of thought in our above summary: individual results should be returned if participants do so wish. We believe that the situation in the case of paediatric biobanks enrolling incompetent minors is slightly different, as the persons making this choice are not the participants themselves.

First, we believe the right not to know does not apply to parents with regard to information for early-onset treatable or preventable diseases. In the case of paediatric biobanks, if the biobank has a policy to return such information, with the option of opting out, this option should not be made available if the consent form is filled out by the parents of under-age participants. We agree that competent adults have the right not to know their genetic status, even if this can save their own lives. In this respect we follow the paper by Andorno ${ }^{25}$ that this right not to know is based on autonomy and on people's interest in not being psychologically harmed by the results of genetic tests or genetic research. Our situation of parents deciding for their children is somewhat different, in the sense that the decision is made for a third person. The autonomy in question is thus that of the parent and not of the child, and is always limited by considerations about the best interest of the child. It is not unthinkable that some parents might opt out of receiving such information as a result of magical thinking ('ignorance is bliss'). Although there are many areas in which parental decisions should not be questioned, this is one area in which others can take the decision to return information, even against the parents' wishes. Take the example of familial adenomatous polyposis (FAP). Early detection of mutations in the APC gene can lead to screening for colonic and extracolonic tumours and can be potentially lifesaving. ${ }^{26}$ A parent does not have the right of opting out of receiving such information about his or her child.

Second, based on the principle of respect for participant's autonomy and the right to know, some biobanks may have the option to provide access to participants to all their individual genetic information if they do so want. However, this should not apply when parents have enrolled their children in the biobank. In the clinical context, literature on genetic screening 
and testing of minors has amply discussed the negative sideeffects of allowing parents access to non-crucial genetic information. On a practical level, knowing that a child carries a certain gene associated with a condition later in life may cause anxiety in a family. Parents may start treating their children as if they already have the condition. ${ }^{27} 28$ Carrier status may be interpreted as having an effect on their child's health. On a more theoretical level, children should have a right to an open future, ${ }^{29}$ to decide on the information they want to know about themselves when they are ready to do so, and be shielded from too much curiosity from their parents' side. We believe, based on these data, that allowing parents full access to all genetic data of their children, possibly out of respect for parental autonomy, is not in the best interest of the children in question and should be prohibited.

In a research context, the same considerations apply. One guideline on research on human tissue of the UK Medical Research Council' ${ }^{30}$ even explicitly specifies that 'Tests of known predictive value for adult-onset diseases should not be done for research purposes on individually identifiable samples from children'. Even if anonymous epidemiological research on such diseases may, for practical purposes, in some cases be allowed on paediatric samples such as DNA from blood spot cards, we agree that the same restrictions should apply with regard to return of individual research findings. If postponing the access to such information does not deprive children of possible preventable treatment, it should be delayed until later and left to the choice of the participant when he or she becomes an adult. ${ }^{31}$ Some may argue that there can be some benefit in knowing early-onset unpreventable or untreatable disorders. ${ }^{31}$ However, these benefits are not completely transparent, and as we are speaking here of non-sought-for information in a research context, we believe such information should not be communicated.

In the case of research on stored tissue samples and data, a complicating issue is the fact that such tissue samples are often stored for longer periods of time, and that the research can continue after the child has reached the age of competence. At this point, the participant should be allowed to make the same decisions as other 'adult' participants. If the biobank gives web access to participants to their genetic data, this should be given to participants when they turn 18 years of age.

\section{Duty of researchers}

Up till now, our suggestions focused on the right (not) to know and on participant's autonomy. However, a difficult question is still untouched: is a 'no individual results shall be returned' policy for adults, like that of the UK Biobank still defensible when children are concerned? As we have seen before, the advocates of such a position (our first 'line of arguments') refer to the fact that genetic results are inconclusive and can cause anxiety, the therapeutic misconception, the duty to solidarity to participate (and not expect anything back) and the fact that the administrative burden of a policy of returning results would stall important research.

The first argument refers to the fact that genetic results are inconclusive and cause anxiety. However, for well-known earlyonset treatable or preventable conditions this argument does not hold. Of course communication of such information may never be only communication of the plain facts, and may thus be outside of the researcher's competence. We observe that the genetic research children participate in is often of the type of a longitudinal cohort study, which allows for frequent contact with researchers and research nurses. Or children who already have a medical condition are enrolled through their physician or clinical geneticist. Therefore, the infrastructure for good followup is already there. Moreover, there is a fundamental difference between adult and paediatric research participants. The latter have limited autonomy and are as such vulnerable. They have not enrolled themselves in the research, and as such it is acknowledged that they are in need of extra protection. In the literature on clinical trials, there is often the requirement that research on children should be for the benefit of children. ${ }^{32}$ Although we admit that research on paediatric tissue samples is different from clinical trials due to the minimal physical risk involved, we think that the communication of findings of earlyonset treatable and preventable diseases can be interpreted as a benefit in this context. In this respect, the 'therapeutic misconception' argument is also flawed. We agree that parents and children should be aware that research is not done for their own benefit; we do not believe that this potential misconception is enough reason not to return important health information about vulnerable participants.

This relation between vulnerability and benefit requires some further elaboration. A concept that can be of help here is the 'duty of care' of researchers. In this respect, the term 'ancillary care' has been framed. Such care is care that is not required to make a study scientifically valid. For example, the following up on a diagnosis found by protocol tests or treating ailments that are unrelated to the study's aim would be ancillary care. ${ }^{33} 34$ The return of findings about early-onset treatable or preventable diseases in genetic studies fits this description. This model is based on the fact that the relationship between participant and researcher involves a partial entrustment of the former's health to the latter. Indeed, participants entrust medical information and samples to researchers, and the informed consent process transfers rights to use these to researchers. In this respect participants are vulnerable to researchers. Richardson and Belsky ${ }^{34}$ acknowledge a general duty to act compassionately towards the needy, vulnerable and dependent. However, given the research context, this duty is limited to specific aspects of the participant's health. A researcher is not responsible for all aspects of the health of participants, only those that arise within the study. The strength of the ancillary care duty is moreover influenced by different factors, such as the participants' vulnerability, the risks and burdens of the study, the depth of the relationship between the researchers and participants and the modes of alternative access. Do participants have other means to obtain the same information?

We think that this ancillary care model is specifically applicable to children in genetic research. First, genetic information is not typically acquired in ordinary health care. Second, many of such research, when done on children, involves a close contact between researchers and under-age participants. Third, children are recognised as a vulnerable population, which would make them especially entitled to ancillary care from researchers. Richardson and Belsky ${ }^{34}$ link the vulnerability of research participants to the fact that they transfer certain aspects of their health to researchers. With children, this is further complicated by the fact that they often do not make the decision to participate themselves. Indeed, vulnerability in children is linked to their lack of autonomy. As we do not know (with small children) what their choice would be, or as their current choice (as an older child) may not be their 'definite' one, children may seem vulnerable in their choices. Indeed, we should prevent them from making choices that are too definite and that would close down other options later on. ${ }^{29}$ Therefore, the fact that the participants are children would make the ancillary care duty higher in the case of paediatric biobanks. 
We think returning results about early-onset treatable and preventable diseases could also satisfy the requirement that research should be somehow beneficial to children. True, such research is potentially beneficial to children in general. However, the fact that these participants are even more vulnerable, because they have a limited autonomy, may suggest that there should also be some limited personal benefit. Such benefit may be interpreted in many ways, but we think the opportunity to be informed of potentially severe conditions suits this purpose better than, for example, a monetary compensation. Indeed, as is argued by Brock, ${ }^{35}$ children may even have a higher claim to health care than do adults. This is again linked to their vulnerability, which also consists of the fact that they do not understand their own need, and cannot provide for their own health care, unlike consenting adult participants. Therefore, he argues, access to health care is not enough, we must make sure children actually receive it. ${ }^{35}$ Although it is true that paediatric biobanks are not diagnostic tools, we believe these reflections do enhance the ancillary care duty of researchers to provide information about early-onset treatable and preventable diseases, if they accidentally stumble upon it.

The third argument, that of solidarity is also problematical. The principle of solidarity has been used by some authors to suggest that participants should participate in biobank research without expecting anything back. ${ }^{36} 37$ However, the principle of solidarity cannot be applied without restrictions to children. ${ }^{37}$ Children are exempt from certain duties such as paying taxes and having a job, although other civilised behaviour is expected from them. At least researchers have the right to appeal to children to participate in biobank research. This does not automatically entail that children need to participate without expecting any benefit back, especially if this in the form of found information about preventable or treatable disorders. Moreover, solidarity has an additional meaning, referring to the idea that the weakest and most vulnerable in society should be protected and some of their burdens should be carried by others. Although it is true that biobank research is not so invasive or burdensome that children should be exempted from being solidary in this respect altogether, they may be compensated by at least providing them with information.

The fourth argument may make the most sense. In some context, such as (anonymous) epidemiology on blood spot cards it may be unfeasible to provide individual results because the infrastructure is not there. We agree with Affleck, ${ }^{14}$ that in the context of pure economics, a policy of not returning results may be allowed. We might extend this argument even for paediatric biobanks, especially if the burden for the children is very low and the contact between researchers and children is minimal, as is sometimes the case for research on older, archived collections. Related to this, the duty to return individual results is higher if a GP or a clinician who is in frequent contact with the patient is involved in the recruitment of the samples than if the recruitment is done by a researcher or a research nurse and there is no further contact with donors afterwards. However, deciding not to return individual results may never be just an easy way out: if the subjects are incompetent minors, the issue of returning individual results may require even more consideration for incompetent minors than when adults are concerned, because the former are vulnerable research subjects with limited autonomy. This is especially the case in contexts in which there is a frequent contact between minors and the research institute.

\section{CONCLUSIONS AND RECOMMENDATIONS}

We have distilled two dimensions from the discussion on return of individual results in a genetic research context: the respect for a participant's autonomy and the duty of the researcher. Starting from these two dimensions, we have investigated what is different if the research participants are minors, and have concluded that the arguments pro or con return of individual results are somewhat different here. With respect to the first dimension, we believe that parents should not be allowed to opt out of receiving information about preventable or treatable early-onset conditions, but they should also not be given access to any and all genetic data research may produce. As for the second dimension, because children have a special status in research, traditional arguments such as those about therapeutic misconception or solidarity seem flawed, and the duty to return results that yield important health benefits is greater than with adult participants. Still, in projects that require no extra contact with participants such as epidemiology on blood spot cards, and that do not have the appropriate infrastructure, logistic considerations may push the pendulum towards the decision not to return individual results.

We understand that by using the example of the small incompetent child we are oversimplifying matters. Considering an older child or a teenager would have to include a decision whether he or she can or cannot understand what is at stake. The issue is even more complex when inheritable diseases are at stake: the age that people can reproduce is lower than the generally accepted age of majority. To what extent should the communication of inheritable, but late-onset diseases correspond to the age of sexual maturity? Also, as new genes are discovered and new treatments are possible, the situation may become more complex, and more and more genetic variants may show up that would warrant communication. For example, there is increasing evidence that aneurysm has a genetic component. ${ }^{38}$ If such evidence becomes conclusive, this would be a good example that should be communicated, even at an early date. We also think that guidelines for biobank research on paediatric stored tissue should tackle the issue of the return of individual results separately when children are concerned. In particular we propose the following:

- Researchers should return information to parents and children about early-onset treatable or preventable diseases, unless there are compelling reasons not to do so.

- If the biobank has a general 'tick box' option to allow the participant to choose whether to receive information or not, this tick box should not be available to parents on behalf of their children.

- All other results should be postponed until the child is 18 years of age. At that point, the return of results policy should be renegotiated with the participant. This is preferably systematically done but at least before any communication about health information is done.

Acknowledgements The authors would like to thank the anonymous reviewer for his or her comments.

Funding This work was supported by FWO Flanders, project number G029107.

Competing interests None.

Provenance and peer review Not commissioned; externally peer reviewed.

\section{REFERENCES}

1. Hens K, Nys H, Cassiman JJ, et al. Biological sample collections from minors for genetic research: a systematic review of guidelines and position papers. Eur J Hum Genet 2009;17:979-90. 
2. Hens $\mathbf{K}, \mathrm{Nys} \mathbf{H}$, Cassiman $\mathrm{JJ}$, et al. Genetic research on stored tissue samples from minors: a systematic review of the ethical literature. Am J Med Genet $A$ 2009;149A:2346-58

3. Gurwitz D, Fortier I, Lunshof JE, et al. Children and population biobanks. Science 2009; $325: 818-19$

4. Hens K, Wright J, Dierickx K. Biobanks: oversight offers protection. Science 2009;326:798-9.

5. Hansson MG, Maschke KJ. Biobanks: questioning distinctions. Science 2009;326:797.

6. Brothers KB, Clayton EW. Biobanks: too long to wait for consent. Science 2009; 326:798.

7. Hansson MG. Ethics and biobanks. Br J Cancer 2008;100:8-12.

8. Wolf SM. Introduction: the challenge of incidental findings. J Law Med Ethics 2008; $36: 216-18$

9. Choy KW, Setlur SR, Lee C, et al. The impact of human copy number variation on a new era of genetic testing. BJOG-Int J Obstet Gy 2010:117:391-8.

10. Tabor HK, Cho MK. Ethical implications of array comparative genomic hybridization in complex phenotypes: points to consider in research. Genet Med 2007:9:626-31.

11. Kaye J, Boddington P, de VJ, et al. Ethical implications of the use of whole genome methods in medical research. Eur J Hum Genet 2010;18:398-403.

12. Lawrenz F, Sobotka S. Empirical analysis of current approaches to incidental findings. J Law Med Ethics 2008;36:249-55; 211.

13. Forsberg JS, Hansson MG, Eriksson S. Changing perspectives in biobank research: from individual rights to concerns about public health regarding the return of results. Eur J Hum Genet 2009;17:1544-9.

14. Affleck P. Is it ethical to deny genetic research participants individualised results? $J$ Med Ethics 2009;35:209-13.

15. Johnston C, Kaye J. Does the UK biobank have a legal obligation to feedback individual findings to participants? Med Law Rev 2004:12:239-67.

16. Shalowitz DI, Miller FG. Disclosing individual results of clinical research: implications of respect for participants. JAMA 2005;294:737-40.

17. Murphy J, Scott J, Kaufman D, et al. Public expectations for return of results from large-cohort genetic research. Am J Bioeth 2008;8:36-43.

18. Council for International Organization of Medical Sciences (CIOMS). International guidelines for ethical review of epidemiological studies. Geneva: Council for International Organization of Medical Sciences, 1991.

19. World Health Organization (WHO). Genetic databases: assessing the benefits and the impact on human and patient rights. Geneva: World Health Organization, 2003.

20. Bookman EB, Langehorne A, Eckfeldt $J$, et al. Reporting genetic results in research studies: summary and recommendations of an NHLBl working group 199. Am J Med Genet 2006;140:1033-40.
21. Richardson HS. Incidental findings and ancillary-care obligations 1. J Law Med Ethics 2008;36:256-70; 211

22. Knoppers BM, Joly Y, Simard J, et al. The emergence of an ethical duty to disclose genetic research results: international perspectives. Eur J Hum Genet 2006;14:1170-8.

23. Ravitsky V, Wilfond BS. Disclosing individual genetic results to research participants. Am J Bioeth 2006;6:8-17.

24. Rothstein MA. Tiered disclosure options promote the autonomy and well-being of research subjects. Am J Bioeth 2006;6:20-1.

25. Andorno R. The right not to know: an autonomy based approach. J Med Ethics 2004;30:435-9.

26. Jarvinen HJ. Genetic testing for polyposis: practical and ethical aspects. Gut 2003;52(Suppl 2):ii19-22.

27. Avard DM, Knoppers BM. Ethical dimensions of genetics in pediatric neurology: a look into the future. Semin Pediatr Neurol 2002;9:53-61.

28. Burke W, Diekema DS. Ethical issues arising from the participation of children in genetic research. J Pediatr 2006:149(1 Suppl):S34-8.

29. Feinberg J. The child's right to an open future. In: Aiken W, LaFollette $H$, eds. Whose child? Children's rights, parental authority and state power. Totowa: Rowman and Littlefield, 1980:124-53.

30. Medical Research Council. Human tissue and biological samples for use in research: operational and ethical guidelines. London: MRC, 2001.

31. Borry P, Evers-Kiebooms G, Cornel MC, et al. Genetic testing in asymptomatic minors: background considerations towards ESHG recommendations. Eur J Hum Genet 2009;17:711-19.

32. Pinxten W, Dierickx K, Nys H. Ethical principles and legal requirements for pediatric research in the EU: an analysis of the European normative and legal framework surrounding pediatric clinical trials. Eur J Pediatr 2009;168:1225-34.

33. Belsky L, Richardson HS. Medical researchers' ancillary clinical care responsibilities BMJ 2004;328:1494-6.

34. Richardson HS, Belsky L. The ancillary-care responsibilities of medical researchers. An ethical framework for thinking about the clinical care that researchers owe their subjects. Hastings Cent Rep 2004;34:25-33.

35. Brock DW. Children's rights to health care. J Med Philos 2001;26:163-77.

36. Chadwick R, Berg K. Solidarity and equity: new ethical frameworks for genetic databases. Nat Rev Genet 2001;2:318-21.

37. Harris J. Scientific research is a moral duty. J Med Ethics 2005;31:242-8.

38. Ruigrok YM, Elias R, Wijmenga C, et al. A comparison of genetic chromosomal loci for intracranial, thoracic aortic, and abdominal aortic aneurysms in search of common genetic risk factors 1. Cardiovasc Pathol 2008;17:40-7. 


\section{The return of individual research findings in paediatric genetic research}

Kristien Hens, Herman Nys, Jean-Jacques Cassiman, et al.

$J$ Med Ethics 2011 37: 179-183

doi: 10.1136/jme.2010.037473

Updated information and services can be found at:

http://jme.bmj.com/content/37/3/179.full.html

\section{These include:}

References This article cites 34 articles, 11 of which can be accessed free at: http://jme.bmj.com/content/37/3/179.full.html\#ref-list-1

Email alerting
service

Receive free email alerts when new articles cite this article. Sign up in the box at the top right corner of the online article.

Notes

To request permissions go to:

http://group.bmj.com/group/rights-licensing/permissions

To order reprints go to:

http://journals.bmj.com/cgi/reprintform

To subscribe to BMJ go to:

http://group.bmj.com/subscribe/ 